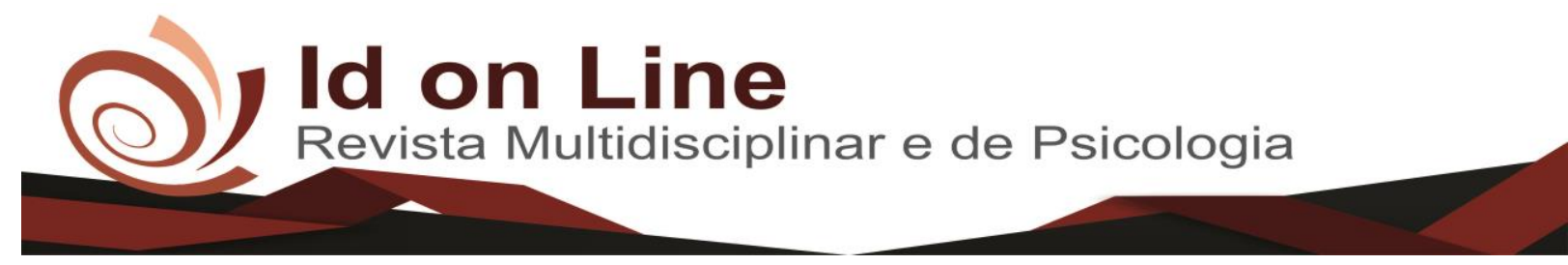

Artigo

\title{
O Debate Criminológico e Dogmático sobre a Incidência do Terrorismo no Direito Penal Brasileiro
}

\author{
Cícera Rosana da Silval/ Miguel Melo Ifadireó / José Antônio de Albuquerque Filho ${ }^{3}$
}

\begin{abstract}
Resumo: Este artigo apresenta alguns pontos de tensão oriundos dos debates criminológicos e dogmáticos sobre a incidência do terrorismo no direito penal brasileiro. Buscou compreender os processos da produção da representação social da violência pelo terrorismo internacional e verificar se os contemporâneos mecanismos disponíveis são capazes de se oporem e de conterem o avanço do terror internacional. A metodologia utilizada no trabalho pautou-se em revisão de literatura, uma vez que foi realizada com base em análise de obras doutrinárias, leis nacionais e estrangeiras com uso do método de procedimento exploratório e descritivo. Fundamentou-se no percurso metodológico para o aprofundamento do conhecimento sobre as soluções a serem percorridos durante a análise. O tipo de estudo exploratório descritivo permitiu identificar e obter uma melhor compreensão do comportamento dos diversos fatores e elementos que influenciam e determinam o fenômeno do terror em estudo. A partir desses aspectos teórico-metodológicos, bem com diante da análise das leis, dos discursões doutrinárias e questionamentos apresentados por críticos de diversos países, foi possível concluir, por um lado, que a luta contra o terror é um enfrentamento árduo; por outro lado, compreendeu-se que houve uma notável evolução na disseminação das ideias motivadoras de legislações antiterrorismo, uma vez que, o terrorista moderno não tem característica física, a ideia do homem bomba solitário é uma percepção superada diante da pulverização do medo alastrado pelo terrorismo..
\end{abstract}

Palavras-chave: Terrorismo. Leis Antiterrorismo. Repressão ao Terror. Dogmática do Direito Penal do Inimigo. Criminologia crítica.

\section{The Criminological and Dogmatic Debate on the Incidence of Terrorism in Brazilian Criminal Law}

\begin{abstract}
This article presents some points of tension stemming from the criminological and dogmatic debates on the incidence of terrorism in Brazilian criminal law. It sought to understand the processes of production of the social representation of violence by international terrorism and to verify if the contemporary mechanisms available are capable of opposing and containing the advance of international terror. The methodology used in the study was based on literature review, since it was carried out based on analysis of doctrinal works, national and foreign laws using the exploratory and descriptive procedure method. It was based on the methodological course to deepen the knowledge about the solutions to be covered during the analysis. The type of exploratory descriptive study allowed
\end{abstract}

\footnotetext{
1 Pós-Graduanda em Direito Penal pela Pontifícia Universidade Católica (PUC/MG). Graduação-Bacharelado em Direito pelo Centro Universitário Dr. Leão Sampaio (UNILEÃO). Servidora Pública lotada na Promotoria de Combate à Violência Doméstica e Familiar em Juazeiro do Norte. Pesquisadora do Laboratório Interdisciplinar de Estudos da Violência (LIEV) na Linha 01 - Criminologia e Segurança Pública do Centro Universitário Dr. Leão Sampaio. Endereço eletrônico: rosana_braz@ hotmail.com.br;

${ }^{2}$ Doutor em Sociologia (UFPE). Mestre em Criminologia Internacional e Europeia (UNIHAMBURG/ ALEMANHA). Mestre em Educação e Antropologia (UNIHAMBURG/ ALEMANHA). Graduação-Bacharelado em Direito (UNIFOR). Graduação-Licenciatura (FAK). Professor efetivo assistente do Curso de Administração da Universidade de Pernambuco (UPE). Professor horista do curso de Direito do Centro Universitário Dr. Leão Sampaio (UNILEÃO). Professor temporário da Faculdade de Ciências Humanas do Sertão Central (FACHUSC). Pesquisador-líder do Laboratório Interdisciplinar em Estudos da Violência na Linha de Pesquisa 01 - Criminologia e Segurança Pública. Endereço eletrônico: crioulo.miguelangelo.melo@gmail.com.;

${ }^{3}$ Doutorando pelo Programa de Pós-Graduação em Letras da Universidade do Estado do Rio Grande do Norte. Mestre em Direito pela Universidade Católica de Pernambuco. Professor substituto do curso de Direito da Faculdade de Ciências Humanas do Sertão Central (FACHUSC). Professor do curso de Direito da Faculdade São Francisco da Paraíba (FASP). Professor do curso de Direito da Faculdade de Filosofia, Ciências e Letras de Cajazeiras (FAFIC). Pesquisador-colaborador do Laboratório Interdisciplinar em Estudos da Violência no Centro Universitário Dr. Leão Sampaio (LIEV-UNILEÃO). E-mail: albuquerque_filho@ @otmail.com.
}

561 Id on Line Rev. Mult. Psic. V.12, N. 42, p. 561-583, 2018 - ISSN 1981-1179

Edição eletrônica em http://idonline.emnuvens.com.br/id 
to identify and obtain a better understanding of the behavior of the various factors and elements that influence and determine the phenomenon of terror under study. From these theoretical-methodological aspects, as well as from the analysis of laws, doctrinal discourses and questionings presented by critics of several countries, it was possible to conclude, on the one hand, that the fight against terror is a hard confrontation; On the other hand, it was understood that there was a notable evolution in the dissemination of the ideas motivating counter-terrorism legislation, since the modern terrorist has no physical characteristic, the idea of the solitary bomb man is a perception overcome by the spraying of fear spread by the terrorism..

Keywords: Terrorism. Antiterrorism laws. Repression to Terror. Dogmatics of the Criminal Law of the Enemy. Criminology Critical.

\section{Considerações Iniciais}

Nos EUA, em 11 de setembro de 2001, dois aviões americanos são direcionados contra as Torres Gêmeas do World Trade Center, em Nova York, várias milhares de pessoas morreram, exatamente porque se levantaram a tempo de ir para o trabalho; porque elas não ficaram presas em um engarrafamento qualquer nas ruas da Metrópole Nova York naquele dia; porque elas ganhavam os seus sustentos no edifício que era um símbolo do capitalismo norteamericano; porque representavam um estilo de vida diferente, dirigido e ostentador do desejo de sucesso impulsionado pelo american dream; porque compactuavam com os signnos de prestígios e de poder; porque repetiam os valores morais da superpotência mundial que se opunha de encontro aos desjosos pelos agressores. (BODE, 2002).

John Arquilla e David Ronfeldt (2001) apontam que as organizações terroristas internacionais vão se fortalecendo e se (re-) estruturando, causando pânico na sociedade internacional, organizações criminosas, entre estas se podem enumerar: Yakuza, Cosa Nostra, Forças Revolucionárias Colombianas, Cartel de Cali ou de Medellin, Comando Vermelho, Primeiro Comando da Capital, sendem lugar no cenário criminal internacinal para modernas organizações terrotistas (globais) estruturas e hierarquizadas com presença marcante nas redes sociais, tais como: a) The Lord's Resistance Army/LRA (Uganda, República Centro-Africana, República Democrática do Congo, e partes do sul do Sudão); b) Tehrik-e Taliban Pakistan (Paquistão e Afeganistão); c) Lashkar-e-Tayyiba/ LT (Paquistão e Índia); d) Al-Shabaab (Leste da África); e) Hezbollah (Israel e Líbano); f) Boko Haram (África Ocidental, principalmente 
na Nigéria e Niger); g) Taliban (Afeganistão); h) Estado Islâmico/ EIIS-ISIS (Iraque, Síria, Palestina e na maior parte do Oriente Médio, ultimamente está descentralizado com células no mundo inteiro); e finalmente, i) O mais famoso de todos os grupos terroristas o Al-Qaeda (descentralizado com células no mundo inteiro).

A partir da exposição inicial da questão problema "terrorismo e lei antiterrorismo" e da relevância de se promover o diálogo entre as ciências do Direito Penal e a abordagem interacionista simbólica da Criminologia crítica, verificamos que o tema da violência, bem como do terror e, respectivamente, do terrorismo fazem parte da história da sociedade mundial e da brasileira. A violência e o terror há muito tempo, já vêm sendo objeto de distintos estudos pelas mais diferentes ciências sociais, humanas e jurídicas. Dessa maneira, estudar o terrorismo sob o foco dialogismo em dois distintos olhares - penal e criminológico - constitui-se a justificativa do presente trabalho, uma vez que este se volta, por um lado, para as representações do terrorismo na contemporaneidade, em seu aspecto específico e simbólico; e por outro lado, devido aos episódios cotidianos do terrorismo internacional, a violência e o terror motivadas pela xenofobia em relação ao Outro, tornaram-se mundialmente objeto das lentes da ciência penal e do direito penal internacional, principalmente, diante do espraiamento e da visibilidade que a mídia internacional vem dando em suas manchetes aos atentados pós-11 de setembro de 2001 em Nova York. Neste diapasão fenomenológico da violência do terror, destacam-se os diversos episódios e semelhantes ataques terroristas, os quais em comum têm o modus operandi e a propagação do ódio xenofóbico ao Outro, a saber destacam-se as ações de terror em Islândia (2002), em Espanha/ Madrid (2004), em Inglaterra/ Londres (2005 e 2011), em Noruega (2005), em França/ Toulouse (2012), em Bélgica/ Bruxelas (2014 e 2016), em França/ Paris (2014), em Alemanha/ Würzburg/ Munique e Ansabach (2016).

Este artigo busca, em primeiro lugar, compreender o processo da produção da representação social da violência pelo terrorismo internacional, ou seja, na esfera macrocriminológia, se propondo assim, a analisar criticamente, se os contemporâneos mecanismos disponíveis - tanto na sociedade quanto na ordem jurídica internacional - são capazes de se oporem e de conterem o avanço do terror internacional; em segundo lugar, ele se direciona a analisar a construção da legislação antiterror ódio na esfera microcriminológica, e as suas consequentes estratégias de políticas públicas nacionais de segurança. Para melhor compreensão do tema pesquisado, parte se do pressuposto de que a discussão em tela, em torno

563 Id on Line Rev. Mult. Psic. V.12, N. 42, p. 561-583, 2018 - ISSN 1981-1179 Edição eletrônica em http://idonline.emnuvens.com.br/id 
dos crimes de terrorismo, acompanham o cenário (inter)nacional, quando estas, se direcionam ao tratamento de problemas específicos a partir da propagação do ódio na sociedade e nas comunidades internacionais. Como método de abordagem se decidiu pela utilização da abordagem qualitativa com o uso do método dialético. (MARCONI; LAKATOS, 2001).

Como método de procedimento, se foi feito uso de métodos exploratório e descritivo, pois, baseado na pesquisa bibliográfica, por ser o melhor percurso metodológico para o aprofundamento do conhecimento sobre as soluções a serem percorridos durante a pesquisa. $\mathrm{O}$ tipo de estudo exploratório descritivo permitiu identificar e obter uma melhor compreensão do comportamento dos diversos fatores e elementos que influenciam e determinam o fenômeno do terror em estudo. (ANDRADE, 1997).

\section{Reflexos do Terrorismo na Sociedade e nas Comunidades Internacionais}

Com o advento do fim da guerra fria - bloco capitalista e socialista - a economia mundial em tempos de globalização reconhece a primazia da ditadura do capital sobre a ditadura do proletariado, e toda a ação política em si e per si originária do bloco socialista passa a ser vista como atrasada ou em razante declínio político-econômico. O capitalismo vence a batalha ideológica, originando-se assim, novos problemas como o considerável aumento do fluxo de migrações para o continente europeu e norte americano, despertando os governos em tela, a desenvolverem ações políticas específicas, não apenas a nivel de segurança interna, como também, de controle contra o aumento das migrações internacionais dos países pobres para a "rica” Europa, EUA e Canadá. (JACOBS; HENRY, 1996). Tornando-se assim, necessário saber, quem seriam os imigrantes que estavam "adentrando aos ricos Estados" e qual a procedência, religiosa, étnico-racial, sexual e de orientação sexual destes que desastibilizariam, por suas diferenças, a identidade e as normas de comportamento cultural, social e juridicamente instituidas (WOODWARD, 2011).

A sociedade internacional, bem como, as comunidades regionais vem se perguntando, quais seriam os critérios jurídicos para abordar a legitimidade e/ ou ilegalidade da migração, que finda por desaguar em migrantes desejáveis e indesejáveis. (JACOBS, POTTER, 1998). Dando-se uma produção de estigmas e rótulos sobre a recepção migratória entre uma real e 
ideal, entre uma real e virtual, como sugere Goffman ao apontar os mecanismos utilizados na produção de estigmas e atrbutos sobre a identidade social dos indivíduos (GOFFMAN, 1978). Assim, a luta contra o ódio torna-se o novo e o emergente motor de campanhas nacionalistas em muitos países do mundo ocidental - detentores não apenas das maiores economias mundiais, como também, da moralidade e das premissas de civilidade - principalmente, depois do hostil e devastador ataque terrorista dos "11 de setembro" (PERRY, 2011). Este processo levou a sociedade internacional a despertar para o acirrado debate a respeito da necessidade de endurecimento da legislação penal (inter)nacional, e consequentemente, do tratamento diferenciado à tipos especificos de delinquentes - terroristas, as facções criminosas, os pedófilos, os traficantes etc - conforme passou a preconizar va a doutrina penal conservadora (JAKOBS, 2009; 19830, a partir do uso de medidas de segurança de contenção que habilitariam a partir de então o considerável aumento do poder punitivo do Estado, habilitando-o a tratar de forma desigual os cidãdãos e os inimigos dos cidadãos, ou seja, os inimigos do Estado (JAKOBS, 2003).

Ao tratar dos reflexos do terrorismo na comunidade internacional não devemos se ater ao conceito técnico e exatamente aproximado dos quais foram abordados no tópico anterior. Afastar-se da temática sociológica e jurídica da nomenclatura seria fechar os olhos para a realidade da diversificação sociocultural das motivações dos atos terroristas. Certo é que a classificação de "terrorismo" para todo ato violento cometido, põe em risco uma disseminação errônea do que é esse mal que acomete a humanidade e o seu combate passa a legitimar movimentos e lutas sociais que são válidas e legitimas, mas que em decorrência de tal banalização conceitual, ou peculiaridades nacionalistas vinculadas a cada conceituação, desvirtua as políticas de enfrentamentos pelos países que se dispõem. (JAKOBS, 1992). O terrorismo internacional apresenta-se nas comunidades internacionais, como por exemplo, na União Europeia (EU) como um dos maiores desafios, repletos de problemas e carentes de novas ressignificações, uma vez que as dificuldades começam com o fato de que até hoje não existe uma definição universal de terrorismo adotada pela comunidade de Estados europeus, muito embora, permaneça a insegurança conceitual que pesa substancialmente, e em particular na descoberta do equilíbrio certo entre a segurança, por um lado (JESCHECK, 2010); a liberdade e o estado de direito, por outro (JESCHECK, 1998). Assim, para combater os perigos do 
terrorismo internacional, o ordenamento jurídico do direito internacional vem buscando utilizar mecanismos propícios para a repressão e prevenção, chamados de sanções inteligentes.

Essas medidas do Conselho de Segurança da ONU (CSONU) são sanções que não são mais dirigidas apenas contra estados, mas contra indivíduos e/ ou associações criminosas de pessoas. (MELO et. al. 2017; FRITZSCH, 2010). De modo que, o regime de sanção previsto pelo Conselho de Segurança da ONU prevê, entre outros mecanismos, a possibilidade do congelamento de todos os recursos financeiros da pessoa em causa ou da associação, com o objetivo de evitar o apoio financeiro às atividades terroristas. Neste sentido, é importante ressaltar que as pessoas suspeitas estão listadas por nome em listas anexadas às Resoluções do Conselho de Segurança da ONU (Resoluções SR) ou, a nível europeu, às posições comuns ou aos regulamentos de implementação. Em vista do fato de que nenhuma proteção adequada dos direitos fundamentais será concedida a nível das Nações Unidas, como proclamam as mais recentes decisões das cortes comunitárias da Europa, a saber, Tribunal Europeu de Justiça, Tribunal Geral da União Europeia e, por fim, Tribunal Europeu dos Direitos Humanos, "apresentando a decisão de elencar em conjunto uma listagem com nomes individuais e de associações criminosas terroristas internacionais". (FRITZSCH, 2010, p. 335).

Antes de adentrar aos comentários sobre os reflexos externos, devemos considerar o ódio que está investido do cometimento de tais atrocidades, mas que não podem ser confundidas com ações de terrorismo. A este respeito, preconizam Miguel Melo, André Almeida, Cícera Silva e Emerson Teixeira (2017), ao tratarem sobre crimes de ódio, enfatizando a violência homofóbica, a intolerância religiosa, o racismo oriundo da sociedade e de políticos nacionais, como asseveram os autores:

\footnotetext{
Em 12 de outubro de 1995 o pastor da Igreja Universal do Reino de Deus Sérgio Von Helder chutou em rede nacional a imagem de Nossa Senhora Aparecida; b) em Julho de 2010 o aprensentador José Luiz Datena da TV Bandeirantes exibiu comentários hostis, relacionando um crime bárbaro ocorrido à "ausência de Deus" na vida do agente, ao ressaltar que "um sujeito que é ateu não tem limites. É por isso que agente vê essses crimes aí"; c) pastor evangélico e ex-presidente da Comissão de Direitos Humanos e Minorias da Câmara dos Deputados, Deputado Marco Feliciano do PSCSP, escreveu em [...]"; e) em 10 de setembro de 2000 João Vicente da Silva de 33 anos foi brutalmente assassinado, teve o pescoço degolado e a cabeça "apedrejada" porque era homossexual; f) em 11 de fevereiro de 2013 o adolescente, homossexual e negro, Kaique Batista foi encontrado morto no centro de São Paulo com marcas de espancamento e com uma barra de ferro enfiada na perna e com todos os dentes arrancados da parte superior da boca [...]. (MELO et al., 2017, p. 141).
} 
Os acontecimentos supracitado são, inquestionavelmente, investido de ódio e ausentes de respeito à condição humana das pessoas vitimadas, dos religiosos que foram publicamente insultados, do cidadão que assiste à sua etnia ter a valoração mitigada em detrimento de achismos e fundamentalismos descabidos. No entanto, até o ano de 2016, tais atos eram tipficados dob a luz do Código Penal Brasileiro, ocorre que, após a publicação da Lei 13.260/2016, conehcida popularmente como "Lei Antiterrorismo", tais condutas passaram a ter uma tipificação mais severa e passaram a ser classificadas como atos terrorista, onde na lei brasileira, o elemento subjetivo penal está atrelado justamente ao ódio, intolerância e desrespeito, mesmo que desprovida de interesse político ou de qualquer enfrentamento governamental. É incontestável que o marco da reflexos global do terrorismo foi midiaticamente vinculado ao atentado ao World Trade Cente, em 11 de setembro de 2001 na Cidade de Nova York. Naquele dia, o Estado Norteamericano não teve apenas prejuízos financeiros somada a perca superior a duas mil vidas. Alí os Estatos Unidos teve a sua moral hegemônica significativamente abalada.

O conceito de inviolabilidade mundialmente disposta estava posto em cheque. O mundo inteiro pode visualizar o terror instalados sob a luz do sol como se a intenção fosse de repassar ao mundo a fragilidade de um país conhecido pela ostentação bélica e financeira. E a reputação no cenário mundial do Estado estava, além de abalada, vinculada à captura do autor confesso da crueldade ali imposta a tantos inocentes. (FRANCE, 2017). A partir de então o terrorismo virou assunto global e o mundo ocidental se sentiu vulnerável a tais ataques. A ideia de segurança havia "virado pó" diante da ousadia e crueldade dos grupos terroristas. (BENEDITES, 2016; SILVA, 2016). O atentado de 11 de setembro também trouxe uma nova nomenclatura, posta como "novo terrorismo" que foi um termo muito utilizado pela imprensa global e que trouxe colocação para que alí se tornasse um marco na história mundial do terrorismo (NUNES, 2017) e também utilizado na abordagem dos atos do ETA - este que idealizava o movimento separadista e independência política dos povos Bascos, bem como pelo Exército Republicano Irlandês, siglado como IRA, o qual também lutava por independência política. (MELO, 2017).

No entanto, tais grupos traziam novas características em seus modos de atuação, utilizando-se da informática para convencimento e treinamento de novos aliados, para compra 
de material bélico e trazendo ainda a disposição ao suicídio por parte dos agentes. ${ }^{4}$ A promoção e a adoção da Lei Antiterrorismo no Brasil vêm desde 2001 gerando grande embate entre as mais distintas esferas da sociedade brasileira, onde de um lado discursos a favor salientam a pressão da sociedade internacional em face do crescimento do crime organizado no país; e por um lado, discursos contra a agenda e o envio da PL 2.016/ 2015 ao Congresso Nacional, levou a incrementação de acirrados debates sob o argumento de que este projeto de lei iria levar, entre outas coisas, a criminalização de movimentos sociais e as manifestações populares, levando a edificação de um estado de exceção e de terror com destaque para o período da ditadura militar. (FRANCE, 2017; NUNES, 2017; SILVA, 2016).

\section{Concepção Hodierna do Terrorismo e Políticas Supressivas}

Muito embora este ato de terror tenha caracterizado e estampado a nível mundial a possibilidade do alcanse do crime de ódio dentro de uma amplitude global nunca vista, despertou o consenso da sociedade internacional a respeito da necessidade de, por um lado, endurecer a legislação penal internacional e o tratamento diferenciado a tipos especificos de crimes. Conforme passou a preconizar a doutrina penal conservadora, a partir do uso de medidas de segurança de contenção e de repressão que habilitariam a um considerável aumento do poder punitivo do Estado, com legitimidade para tratar de forma desigual os cidãdãos e os inimigos dos cidadãos, ou seja, os inimigos do Estado (JAKOBS, 2003); por outro lado, voltou-se a se discutir a necessidade de um ordenamento jurídico internacional hábil para produzir ordens jurídicas normativas com capacidade de centralizar o poder ou com competência para o exercício do controle da segurança internacional. (HAMM, 1994a).

O grande empecilho para que isto ocorra está no próprio fundamento do Direito Internacional Público ao analisar a proposição de uma ordem jurídica centralizada, visando combater o terror e/ou o terrorismo internacional pela propagação de crimes de ódio esbarra na implementação de uma ordem jurídica e política universalizante com competência e legitimidade para impor "princípios e regras destinados a reger as situações que envolvem

\footnotetext{
${ }^{4}$ O Império Vulnerável. Veja, 2001, p.14. 
determinados sujeitos" (MAZZUOLLI, 2015, p. 66), uma vez que a “ordem jurídica na sociedade internacional é descentralizada" diferentemente da que acontece na esfera interna de Estados soberanos (CESSASE, 2006 APUD. MAZZUOLI, 2015). Após a pulverização dos diversos conceitos de terrorismo disseminados pelas mídias e pelas redes sociais, o terror passou a ser inimigo de qualquer um e foi eleito como como inimigo invisível, ou seja, os norteamericanos criaram um adversário sem rosto, pulverizado, impossível de ser pego (GONÇALVES; REIS, 2017). A partir deste ponto são postas definições caracterizadoras e identificadoras da inovação nos atos de terror e dos seus alvos, figurando também a inovação das motivações da provocação do pânico em massa. Jonsival Brito Gonçalves lista como possíveis razões para a transformação do terrorismo hodierno, vejamos:

[...] aparição de inúmeros conflitos étnicos, religiosos e ideológicos em razão da globalização e aproximação entre os povos do mundo; surgimento de novos governos pelo mundo com economias fracas, transformando-se em Estados falidos que não atendem a requisitos mínimos de seus cidadãos; estratégia global, em que algumas nações patrocinam ou fomentam organizações terroristas com o intuito de realizar parte da política externa; • desenvolvimento de novas tecnologias e redução de custos (transportes, comunicações, informática); criação de novas armas, com grande poder de destruição e acessíveis a grupos criminosos; (GONÇALVES; REIS, 2017, p.14).

Desta feita, o legislador brasileiro observou a lacuna legislativa sobre o tema em esteio. Até o ano de 2015, o país só contava com a disposição legal de uma norma constitucional de eficácia limitada, no caso, o texto trazido pela norma pátria, como bem dispõe Débora de Souza Almeida e Fábio Roque Araújo, "Como cediço, o art. 5, XLIII da Constituição Federal tratase de um mandado explícito de criminalização” (ALMEIDA; ARAÚJO, 2017, p.160), ou seja, a constituição liberou para que fossem editadas as normas para dispor sobre o terrorismo através de leis infraconstitucionais, obviamente que observando as limitações principiológicas nela disposta.

\section{Perspectivas do Terrorismo no Ordenamento Jurídico Pátrio}

Abordar as aplicações penais sobre os atos de terrorismo no Brasil é buscar entender porque o legislativo passou a aferir que tais atos deveriam ser criminalizados e sob qual 
perspectiva passaria a ser crime. Além de perceber que as consequências penais impostas pela política de repressão do Estado extrapolam o campo dos princípios constitucionais atrelados à condição de pessoa humana. O Brasil não foi isento da dificuldade de conceituação do que é terrorismo, tanto é que apresenta apenas três registros legais que abordam a temática em esteio. O qual, a princípio, figurou como norma de eficácia limitada incerta no texto constitucional, mais precisamente no Artigo 5. ${ }^{\circ}$, XLIII da Constituição Federal de 1988, o qual trouxe a seguinte redação:

[...] a lei considerará crimes inafiançáveis e insuscetíveis de graça ou anistia a prática da tortura, o tráfico ilícito de entorpecentes e drogas afins, o terrorismo e os definidos como crimes hediondos, por eles respondendo os mandantes, os executores e os que, podendo evitá-los, se omitirem (BRASIL, 1988, s/p.).

Uma norma de eficácia limitada, nos dizeres do constitucionalista Pedro Lenza, são aquelas que não conseguem ou podem por si só, produzir efeitos imediatos, pois necessitam de uma outra norma integrativa, e infraconstitucional, que regulamente e disponha sobre determinado tema. (LENZA, 2017). Outra abordagem legal dada à temática foi a da Lei 7.170/1983 que trata de Segurança Nacional, onde o termo terrorismo foi mencionado em uma lista de condutas típicas elencadas no Artigo 20 de tal lei, in verbis:

\footnotetext{
Devastar, saquear, extorquir, roubar, seqüestrar, manter em cárcere privado, incendiar, depredar, provocar explosão, praticar atentado pessoal ou atos de terrorismo, por inconformismo político ou para obtenção de fundos destinados à manutenção de organizações políticas clandestinas ou subversivas. (BRASIL, 1983, s/p.).
}

Anote-se que, neste contesto, existia uma conotação política atrelada à conduta tipificada como crime contra a segurança nacional, e que o termo "atos de terrorismo" é posto de modo genérico, sem nenhuma especificação do que pudesse vir a figurar esta conduta ali incriminada. Como aduz Renato Brasileiro de Lima, “[...] não permite ao juízo processante a devida adequação formal da conduta com o que se visa combater" (LIMA, 2016, p.982). Anotese que o legislador brasileiro, no que diz respeito à regulamentação do terrorismo no país, permaneceu inerte desde o ano de 1988 até o ano de 2016, quando foi editada e passou a vigorar a popularmente conhecida como "Lei Antiterrorismo" - Lei 13.260/2016. Como já tratado anteriormente, no ano de 2016 o Brasil sediou os jogos olímpicos - evento mundial que seria 
cenário e palco perfeito para as atuações terroristas. E neste cenário seria irrelevante a motivação subjetiva para qualquer atentado, pois os autores terroristas teriam a atenção de grande parte dos olhares dos habitantes deste planeta.

Ocorre que até o ano de 2015 o país não tinha uma lei que pudesse de fato punir, com respaldo ao princípio da anterioridade penal e da legalidade, os autores de um eventual atentado terrorista. E tal questão pressionou a edição da lei antiterrorismo, esta que é grande alvo de críticas doutrinárias quando posta em contraponto ao aparato principiológico e de aplicação processualista vigente no Brasil.

\section{Abordagem Crítica da Lei 13.260/ 2016}

Várias são as interpretações que podem incidir sobre a Lei 13.260/2016 (BRASIL, 2016), principalmente sobre determinados artigos os quais cerceiam abertamente princípios penais e processuais penais consagrados no Direito Brasileiro. Dentre tais interpretações, Débora de Souza Almeida apresenta um leque de possibilidades interpretativa para tal lei, listando-as em "interpretação literal, restritiva, teleológica, sistemática e histórica". (ALMEIDA; ARAÚJO, 2017, p. 161). Rogério Sanches Cunha (2017) apresenta de modo simplista e conclusivo o que vem a ser a interpretação literal, filológica ou gramatical da lei penal ao aduzir que "é a interpretação que considera o sentido literal das palavras, correspondente a sua etimologia” (IDEM, p. 66); Já para a interpretação teleológica, conforme propõe Cunha (2017) ao observar que "perquire a vontade ou intenção objetivada na lei". (IDEM, p. 66); ou seja, que tal método busca, portanto, efetivar o objetivo central da norma, alcançando a efetivação daquilo que a lei busca proporcionar. Para a interpretação histórica, Cunha coloca que "é aquela interpretação que indaga a origem da lei, identificando os fundamentos da sua criação" (IDEM, p.69)., ou seja, considerando os acontecimentos sociais ensejadores de uma vinculação penal para determinados fatos. Por fim, o autor apresenta as ideias de uma interpretação restritiva, uma vez que para ele, esta seria notadamente autoexplicativa. Fato que o autor conceitua como "a interpretação que reduz o alcance das palavras da lei para que corresponda à vontade do texto" (IDEM, 67); restando claro que nesse 
modo de interpretação normativa há uma relação fiel da interpretação ao que está expresso na lei, não deixando espaço para subjetividades.

Justamente por essa vasta disposição de interpretações legais, que pairam diversas discussões sobre a objetividade da lei 13.260/2016, principalmente no que diz respeito a equiparação dos crimes de terrorismo à crimes hediondos. Tal axioma interpretativo decorre da diversidade interpretativa das disposições do Art. $5^{\circ}$, XLIII da Constituição Federal, pois, como já exposto neste trabalho, dispõe que:

\footnotetext{
A lei considerará crimes inafiançáveis e insuscetíveis de graça ou anistia a prática da tortura, o tráfico ilícito de entorpecentes e drogas afins, o terrorismo e os definidos como crimes hediondos, por eles respondendo os mandantes, os executores e os que, podendo evitá-los, se omitirem; (BRASIL, 1988, s/p.)
}

Parte da doutrina discute se a equiparação à hediondez está restrita ao Art. $2^{\circ}$ da Lei 13.260/2016, onde é trazida a conceituação do que é terrorismo e considerando que a Constituição Federal expressa literalmente "o terrorismo", pois Débora de Souza de Almeida defende que a equiparação à crimes hediondos está restrita a prática definida no referido artigo. A doutrina majoritária - entre seus expoentes destacam-se: Débora de Almeida e Fábio Araújo (2017), Luiz Gomes (2017), Rogério Cunha (2017) e Ronaldo Pinto (2017) -, traz a campo o entendimento de que todos os tipos penais da lei antiterrorismo, n. 13.260/ 2016, são equiparados a hediondos. Um discursão mais consistente e lesiva é a questão da criminalização dos atos preparatórios trazida pela lei antiterrorismo. O art. $3^{\circ}$ da Lei 13.260/2026 dispõe de modo claro sobre condutas paralelas ao ato terrorista praticado pelas "organizações terroristas", ou seja, que atuam voltadas para à prática do terrorismo conceituado por esta mesma lei. A disposição legal do art. $3^{\circ}$ da Lei 13.260/2026 traz que "Promover, constituir, integrar ou prestar auxílio, pessoalmente ou por interposta pessoa, a organização terrorista” (BRASIL, 2016) são condutas que, por mais que não sejam em si uma prática de terrorismo nos moldes desta mesma lei, repercutem em penalização, onde a lei estabelece uma "Pena - reclusão, de cinco a oito anos, e multa". A este respeito, Débora de Souza de Almeida acrescenta que:

$\mathrm{O}$ art. $5^{\circ}$ também mostra que seu preceito primário não abriga o crime de terrorismo, mas sim, atos preparatórios deste crime. No caput, observe que na descrição "realizar atos preparatórios de terrorismo com o propósito inequívoco de consumar tal delito" a expressão "tal delito" reporta-se a "terrorismo"; se reescrito, assim resultaria: 
"realizar atos preparatórios de terrorismo com o propósito de praticar atos de terrorismo: I- recrutar [...]; II - fornecer [...]" revela que não tipifica o terrorismo, mas as condutas preparatórias aos atos do art. $2^{\circ}, \S 1^{\circ}$. (ALMEIDA, 2017. p. 164).

A doutrina penal, ao dispor sobre o inter criminis coloca que não se pune os atos preparatórios de um delito, no entanto, já os inícios dos atos executórios podem sim serem punidos na proporção dos danos causados. A esse respeito, os entendimentos são pacificados.

\section{As Velocidades do Direito Penal e a Lei Antiterrorismo no Brasil}

Para tratar das velocidades do direito penal devemos observar que a dinâmica normativa é o acompanhamento das mutações social e das valorações da incidência do Estado nos acontecimentos desordenados, ou seja, das infringências da norma penal. Quem diz o que é crime é a importância de valor investida na avaliação de determinado comportamento, acontecimento ou omissão. De tal modo, o legislador acompanha as novas demandas penais e as consequentes transformações da dogmática penal. Ao analisar a Lei Antiterrorismo (BRASIL, 2016) é bem comum encontrar aspectos que se encaixam no "Direito Penal do Inimigo" do Günter Jakobs (2003), este que Alexandre Rosa de Almeida Moraes aduz ser a “terceira velocidade do direito penal" (MORAES, 2016. p. 13).

Em 1985, até com certo sarcasmo (ao adotar terminologia que facilmente seria hostilizada), JAKOBS pretendia demonstrar que a legislação penal, sobretudo na Alemanha, já estava contaminada por caracteres que ele definia como um modelo de Direito Penal completamente diferente dos paradigmas do modelo liberal- clássico. Em 1999, com a institucionalização e aparente legitimação desses novos parâmetros, em vez de simplesmente legitimá-los e adotá-los (como pretendem fazer crer alguns apressados críticos), JAKOBS parece concluir que o retrocesso aos paradigmas exclusivamente clássicos seria impossível. Dessa forma, advertiu para a necessidade de se delimitar e diferenciar dois modelos de Direito Penal - 'do cidadão' e 'do inimigo', de forma a evitar a completa contaminação do modelo de inspiração iluminista. 5

\footnotetext{
5 MORAES. Alexandre Roxa Almeida de. A Terceira Velocidade do Direito Penal: 'O Direito Penal do Inimigo'. Dissertação (Mestrado em Direito Penal) - Faculdade de Direito da Pontifica Universidade Católica de São Paulo. São Paulo, 2016.p. 1.57
} 
A referida doutrina busca legitimar o tratamento diferenciado para aqueles agentes que incorrem em crimes mais gravosos face ao Estado ou até mesmo aos cidadãos. Ou seja, é a legitimação à um estado de exceção face a gravidade do fato cometido. Como bem preceitua Günter Jakobs (2003) “O Direito Penal do cidadão é o Direito de todos, o Direito Penal do Inimigo é daqueles que constituem contra o inimigo: frente ao inimigo, é só coação física, até chegar à guerra" (IDEM, p. 44). Assim, o autor alemão continua sua tese ao afirmar que "essa coação pode ser limitada em um duplo sentido. Em primeiro lugar, o Estado, não necessariamente, excluirá o inimigo de todos os direitos" (IDEM, p. 44); afirma ainda que, indiretamente, pois ao afirmar que não há supressão a todos os direitos, há um reconhecimento de que na aludida condição há uma mitigação de parte de direitos. Ademais, o autor mantém o seu pensamento ao aduzir que "nesse sentido, o sujeito submetido à custódia de segurança fica incólume em seu papel de proprietário de coisas.

E, em segundo lugar, o Estado não tem porque fazer tudo o que é permitido fazer, mas pode conter-se, em especial, para não fechar a porta a um posterior acordo de paz” (IDEM, p. 45). Buscando este entendimento para os dias atuais, temos que os paradigmas penais de outros tempos, de uma sociedade anteriormente consolidada em princípios que hoje já diferem dos atuais, moldados pelas inovações sociológicas e principiológicas, vemos que a interpretação da sistemática fática requer uma outra atuação estatal, pois aquela que antes era hábil na promoção do controle social, hoje não ampara às demandas decorrentes dos axiomas sociais. Desta feita, a abordagem voltada a legitimar um sistema penal mais invasivo, severo e de exceção recebe a denominação de "Terceira Velocidade do Direito Penal" esta que representa uma evolução na relativização dos direitos e garantias fundamentais do indivíduo em detrimento da preservação e garantia da incolumidade de uma coletividade. Ao tratar das velocidades do direito penal, Rogério Sanches Cunha (2017) pauta tais conceitos no modelo liberal clássico, conforme vejamos:

\begin{abstract}
A primeira, pautada no modelo liberal-clássico, traduz a ideia de um Direito Penal da prisão por excelência, com manutenção rígida dos princípios polótico-criminais iluministas; a segunda, contempla a flexibilização proporcional de algumas garantias penais e processuais, conjugada com a adoção de penas não privativas de liberdade pecuniárias ou restritivas de direitos; já a terceira velocidade, representa um Direito Penal da pena de prisão concorrendo com uma ampla relativização de garantias políticos-criminais, regras de imputação e critérios processuais, que constituem o modelo de 'Direito Penal do Inimigo'. (CUNHA, 2017, p. 148).
\end{abstract}


Essa progressão de velocidades do Direito Penal pautada por Rogério Cunha (2017) ganha respaldo lógico uma vez ser cediço a ineficácia de certas medidas brandas aplicadas às condutas que tenham a sua atuação lesiva. Quando se aborda e enquadra as reprimendas decorrentes da Lei Antiterrorismo (BRASIL, 2016) na 'terceira velocidade do direito penal' é considerado a gravidade das consequências jurídicas e sociais que tal norma penal tenta repreender. Por tal razão, legitimar a supressão de direitos basilares da condição de cidadão detentor de direitos diante das facetas trazidas pelos atos de terror hodiernamente pulverizados nas diversas sociedades, sejam orientais ou ocidentais, é pôr em prática uma política de proteção ao bem comum, qual seja a paz pública e fazer com que a política criminal saia de uma posição de coadjuvante.

\section{Lei 13.2060/2016, um Instrumento de Segurança Pública ou de Repressão Pública?}

É inconteste que o advento da Lei 13.260/2016 veio para afirmar de modo relativamente preciso o que caracteriza a conduta ou ato de terrorismo, expressamente repudiada pela Magna Carta em seu Art. $4^{\circ}$, VIII e para assegurar aos seus nacionais as medidas legais de repressão e prevenção dos atos de terror. E foi exatamente através desta lei que tornou-se possível compreender a forma como nosso ordenamento jurídico vê e trata a gravidade inserida nos crimes de terrorismo, a partir do momento em que o referido diploma legal, em seu Art. 17, trata como equiparado a hediondo todas as condutas nele previstas, não se resumindo apenas ao tipo plurinuclear do art. $2^{\circ}$. Em decorrência da sua vigência, a Lei Antiterrorismo traz a regência do sistema de proteção e de prevenção ao terrorismo, e em algumas das suas previsões legais, destoantes do que já estava posto no convencional sistema penal, a exemplo a possibilidade da prisão preventiva na incidência do agente em atos preparatórios e a própria equiparação integral da lei às condutas hediondas. Outra crítica legalista se pauta na denominada disparidade da dosimetria da pena do financiamento de atos terroristas versus a prática do ato terrorista propriamente dito. Vejamos o que a lei expõe: 
Art. 6. ${ }^{\circ}$ Receber, prover, oferecer, obter, guardar, manter em depósito, solicitar, investir, de qualquer modo, direta ou indiretamente, recursos, ativos, bens, direitos, valores ou serviços de qualquer natureza, para o planejamento, a preparação ou a execução dos crimes previstos nesta Lei: Pena - reclusão, de quinze a trinta anos. Parágrafo único. Incorre na mesma pena quem oferecer ou receber, obtiver, guardar, mantiver em depósito, solicitar, investir ou de qualquer modo contribuir para a obtenção de ativo, bem ou recurso financeiro, com a finalidade de financiar, total ou parcialmente, pessoa, grupo de pessoas, associação, entidade, organização criminosa que tenha como atividade principal ou secundária, mesmo em caráter eventual, a prática dos crimes previstos nesta Lei. (BRAISIL, 2016, s/p. )

A princípio, denota-se ser desproporcional impor uma pena maior a conduta de financiar $\mathrm{o}$ ato à conduta de praticar o ato terrorista que resulta nas consequências inquestionavelmente graves. No entanto, a Lei em comento não detém o objetivo meramente repressivo, mas engloba a política de repressão. É um entendimento sutil, mas financiar os atos de terrorismo atingem, além dos bens jurídicos tutelados nas disposições da Lei 13.260/16, a outros princípios e bens tutelados por outras disposições legais. Financiar o ato terrorista além de promover o terror, patrocina a ideia e a sua disseminação. A este respeito, Débora Almeida ressalta a importância de se interpretar a lei restritivamente ao seu sentido literal, uma vez que a:

[...] interpretação redunda numa falta de razoabilidade quando por exemplo, se compara os arts. $2^{\circ}$ e $6^{\circ}$. Obviamente que o financiamento ao terrorismo (art. $6^{\circ}$.) é crime ainda mais grave do que o ata terrorista (art. $2^{\circ}$ ), tanto que punido mais rigorosamente. Como pode, então, a infração penal menos grave sofrer os rigores da lei 8.072/90, e a mais grave não? (ALMEIDA, 2017. p. 172)

É possível pautar uma conclusão aferindo que para tais crimes a prevenção é um meio de promover uma proteção mais eficaz, evitando-se a proteção deficiente e promovendo a proteção eficaz que deve partir do Estado.

\section{Considerações Finais}

Conforme exposto neste ensaio, existe internamente no Brasil como na Sociedade Internacional, grande preocupação com o estabelecimento de um ordenamento jurídico hábil para lidar com a problemática da propagação dos crimes de ódio oriundos do racismo, da intolerância religiosa, do sexismo e da homofobia. Ao analisarmos o surgimento das primeiras 
legislações específicas sobre os crimes de ódio percebemos que estas surgiram em virtude do ativismo político dos novos movimentos civis americanos, que passaram a exigir do governo dos Estados Unidos da América estratégias de juridicialização, a partir da criação de leis específicas, capazes de criminalizar as ações de exclusão social ou de violência direta e indireta através de condutas ou expressões racistas, sexistas e homofóbicas que ocorriam na sociedade americana entre finais dos anos sessenta e finais dos anos oitenta do século XX.

O presente artigo visou analisar os distintos debates na doutrina entre a Criminologia e o Direito penal, bem como a construção jurídica e a criminalização das ações tipificadas enquanto ações e práticas terroristas em solo brasileiro. Fato este que não apenas deu proeminência e visibilidade aos argumentos que alicerçaram e transformaram este um dos principais temas das agendas de segurança (inter)nacionais após o atentado de 11 de setembro de 2001, a qual colaborou com a materialização de normas jurídicas incriminadoras em distintos ordenamentos jurídicos penais na sociedade internacional contra as práticas terroristas motivadas ou não pelo discurso do ódio. Assim, para análise do presente estudo, a fim de responder à questão problema inicial, questiona-se se tal abordagem, tomando como exemplo a ação terrorista dos 11 de setembro de 2001, seria adequada para se pensar sobre a realidade brasileira, uma vez esta é demarcada por contextos de lutas contra o preconceito, a discriminação e o ódio motivado.

De modo que, se tornou possível, analisar as diferentes formas de exposição da violência, entendemos que as ações direcionadas pela intolerância religiosa, relações étnicoraciais ou comportamentos e orientação sexual de indivíduos, foram se tornando aos poucos, partes de uma agenda global sobre políticas públicas de segurança internacional. Por conseguinte, ressalta-se que o estudo em tela objetivou identificar a gravidade de determinados dispositivos legais da Lei 13.260/2016, a qual é conhecida por "Lei Antiterrorismo" em razão de notadamente serem exceções às normas penais e processuais hodiernamente vigentes no Brasil, contudo, com a evolução das verificações literárias, foi possível identificar pontos além do objetivado e cruciais para o que diz respeito a uma melhor percepção da política de combate ao terrorismo.

Essa "gravidade", ou também ato de lesão à cidadania, teria amparo e partida de comparação na Teoria do Direito Penal do Inimigo de Günter Jakobs, a qual legitimava a aplicação de exceções normativas ao indivíduo a partir da gravidade do ato por ele praticado. 
Ou seja, sob a ótica da teoria de Günter Jakobs, a aplicação legal deve observar o fato cometido e o infrator e com base nisso, seria legítimo abrir exceção para lesões de direitos atrelados a dignidade da pessoa humana. Nesse sentido, Günter Jakobs divide o sistema penal em "Direito Penal do Cidadão" e "Direito Penal do Inimigo", colocando o cidadão em uma bilateralidade e, consequentemente, motivando a legitimação de um sistema penal distinto para aquele que agisse "contra" o Estado. No ano de 2016 o Brasil se viu pressionado diante da recepção aos Jogos Olímpicos, ocasião em que regulamentou, através da lei em comento, as eventuais infrações atinentes à atos terroristas. Ocorre que, a doutrina identifica que na referida lei há lesão a princípios constitucionais tais qual o da dignidade da pessoa humana, o princípio da presunção de inocência e o princípio da isonomia.

Os pontos mais críticos da Lei 13.260/2016 é que ela possibilita a punição de atos preparatórios, o que no sistema penal vigente, até então, não se admitia a punição. Em palavras mais claras, não é possível punir a ideia de cometimento de crime. Mas nessa lei, o ato de tentar comprar materiais explosivos ou armas de potencial poder de destruição, já incidiria no tipo penal e seria, consequentemente, passível de punição. Outra questão é a possibilidade de prisão preventiva sem a precedência do cometimento do crime. Parte da doutrina defende que nessa hipótese estaria sendo lesado o princípio da presunção de inocência, e desobediência aos ditames da Lei que regulamenta a prisão preventiva. As opiniões doutrinárias apresentam-se diversas, contudo, em decorrência da leitura das leis de combate ao terrorismo de alguns países, é possível se verificar que essas denominadas "lesões à direitos" é algo comum na maioria dos textos legais, e que essa permissividade é legitimada pela preservação de direitos de uma coletividade.

Diante da análise das leis, dos discursões doutrinárias e questionamentos apresentados por críticos de diversos países, é possível concluir que a luta contra o terror é um enfrentamento árduo, pois houve uma notável evolução na disseminação das ideias que os motivam. Como já abordado no presente trabalho, o terrorista moderno não tem característica física, a ideia do homem bomba solitário é uma percepção superada diante da pulverização do medo alastrado pelo terrorismo. A partir daí, verifica-se que as colocações trazidas pela Lei Antiterrorismo, embora façam mitigações à direitos subjetivos individuais, ela busca promover além de atos de repressão à lesões em massa, tenta promover uma política de repressão ao terror, e é nesse ponto que ao analisar os pesos e contrapesos que é possível aferir a necessidade de reafirmação da 
legitimidade dos condicionamentos da lei em esteio, pois nesse caso, a defesa não paira sobre direitos subjetivos da condição humana do homem, mas alberga a viabilização e proteção ao direito objetivo da vida, e de uma coletividade. Dado a isto, o presente trabalho vem aferir respaldo ao legislado que permeou diversos princípios constitucionais, processuais e penais para que o Estado tivesse meios de promover a segurança coletiva diante de uma infeliz difusão de terror que assola grande parte do mundo ocidental e oriental.

\section{Referências}

ALCÂNTARA, Priscila Drozdek de. Terrorismo: Uma abordagem conceitual, p. 1-26. Disponível em: $\quad$ http://www.humanas.ufpr.br/portal/nepri/files/2012/04/Terrorismo_Uma-abordagemconceitual.pdf $>$. Acesso em: 30 out. 2017.

ALMEIDA, Débora de Sousa; ARAÚJO, Fábio Roque; GOMES, Luiz Flávio; et al. Terrorismo: Comentários, artigo por artigo à Lei 13.260/2016, Aspectos Criminológicos e PolíticoCriminais. Salvador: Juspodvm, 2017.

ALMEIDA, Débora de Souza; ARAÚJO, Fábio Roque. Terrorismo: Aspectos Criminológico e Político Criminal. 1. Ed. Salvador: JusPodvum, 2017.

ANDERSON, Perry. Balanço do neoliberalismo. In: SABER, Emir; GENTILI, Pablo. Pósneoliberalismo: as políticas sociais e o Estado democrático. São Paulo: Paz e terra, 2005. p. 27-51.

ANDRADE, Maria Margarida de. Introdução à metodologia do trabalho científico. 2. ed. São Paulo: Atlas, 1997.

ANDRADE, R. C. Empreendedorismo: um novo passo em educação. In: ACUCIO, M. R. B. O empreendedorismo na escola. Porto alegre: ARTMED; Belo Horizonte: Rede Pitágoras, 2005. p. $11-20$.

ARELARO L. R. G. Formulação e implementação das políticas públicas em educação e as parcerias público-privadas: impasse democrático ou mistificação da política? Educação \& Sociedade, Campinas, v. 28, n. 1, p. 899-919, out. 2007.

ARQUILLA, John; RONFELDT, David. Networks and Netwars. The Future of Terror, Crime and Militancy. Waschington: Rand Corporation, 2003.

BAKKER, Edwin. Terrorism and Counterterrorism: Comparing Theory and Practice. The Hague. Centre for Terrorism and Counterterrorism, Leiden University, 2013. (Online Course) 
BASQUES, Maria Fernanda Diamante; DINIZ, Clébio Campolina. A industrialização nordestina recente e suas perspectivas. Fortaleza: Banco do Nordeste do Brasil, 2004.

BENEDITES, Afonso. Sob pressão internacional, Câmara aprova lei que tipifica o terrorismo. Proximidade das Olimpíadas e acordo com G-20 fez projeto ter tramitação rápida. Brasília. 25 de fevereiro de 2016. Disponível em: https://brasil.elpais.com > Brasil. Acesso em: 14 de dezembro de 2017.

BODE, Britta. Hate Crimes - Der US-amerikanische Ansatz gegen vorurteilsmotivierte Taten. Dissertação de Mestrado em Criminologia na Universität Hamburg. Orientador: Prof. PD Dr. Reinhard Kreissl, Hamburg: Abril, 2002.

BRASIL, Constituição (1988). Constituição da República Federativa do Brasil. Brasília, DF: Senado, 1988.

BRASIL, Lei 13.260/2016. Disponível em http://www.planalto.gov.br/ccivil_03/_ato20152018/2016/lei/113260.htm. Acesso em: 4. out. 2017.

BRASIL. Art. $5^{\circ}$, XLIII da Constituição Federal. Disponível em <http://www.planalto.gov.br/ccivil_03/constituicao/constituicaocompilado.htm>

BRASIL. Lei n. ${ }^{\circ}$ 13.260, de Março de 2016. Disponível em http://www.planalto.gov.br/ccivil 03/ ato2015-2018/2016/lei/113260.htm. Acesso em: 3. set. 2017.

CANOTILO, J. J. Gomes. Direito Constitucional e Teoria da Constituição. 7 ed. Lisboa: Almedina.

COSTA, Marisa. Cartografando a gurizada da fronteira: novas subjetividades na escola. In: ALBUQUERQUE JÚNIOR, Durval; VEIGANETO, Alfredo; SOUZA FILHO, Alípio. Cartografias de Foucault. Belo Horizonte: Autêntica, 2008. p. 269-294.

COUNTER-TERRORISM AND SECURITY ACT 2015. In: Legislation.gov.uk. The National Archives - Ministry of Justice, United Kingdom. Disponível em <http://www. legislation.gov.uk/ukpga/2000/11/pdfs/ukpga_20000011_en.pdf>. Acesso em: 3.set. 2017.

CUNHA. Rogério Sanches. Manual de Direito Penal Parte Geral. 5 ed. Salvador: Juspodvm, 2017

CURY, Carlos Roberto Jamil. A educação e a nova ordem constitucional. Revista da Associação Nacional de Educação, São Paulo, n. 14, p. 15-11, 2009.

DE LIMA, Renato Brasileiro de. Manual de Processo Penal. 4 ed. Salvador: Juspodivm, 2016.

FOUCAULT, M. Michel. Vigiar e punir: nascimento da prisão. Petrópolis: Vozes, 2006.

FRANCE, Guilherme de Jesus. As origens da Lei Antiterrorismo: os tortuosos caminhos da localização das normas internacionais de combate ao terrorismo no Brasil. Dissertação (Mestrado). 
Escola de Ciências Sociais da Fundação Getúlio Vargas. Programa de Pós-graduação em História, Política e Bens Culturais. 2017.

FRITZSCH, Falke. Sobre o efeito vinculativo da lista de terroristas da UE no contexto das medidas de direito da imigração. [Original: Zur Bindungswirkung der EU-Terrorliste im Rahmen ausländerrechtlicher Maßnahmen] p. 333-340. In: Zeitschrift für Ausländerrecht und Ausländerpolitik (ZAR). 30. Jahrgang. 10/2010. München: Nomos Verlagsgesellschaft.

FRIZZERA Guilherme; SOUZA JUNIOR, José Maria de. Tipificando o Terrorismo no Congresso Brasileiro: os projetos de lei e literatura acadêmica. Brazilian Journal of International Relations, Marília, v. 4, n. 1, p. 111-134, jan/abr. 2015.

GOFFMAN, Erving. Estigma: notas sobre a manipulação da identidade deteriorada. Rio de Janeiro: Zahar, 1978.

GOHN, Maria da Gloria. Movimentos sociais e educação. 2 ed. São Paulo: Cortez, 1994. (Questões da nossa época, n. 5).

GONÇALVES, J.B; REIS, M.V. Terrorismo: conhecimento e combate. São Paulo: Ímpetus, 2017.

GORDON, C.; MILLER, P. (Org.). The Foucault effect: studies in governmentality. Hemel Hempstead: Harvester Wheatsheaf, 1991.

GRECO, Rogério. Curso de Direito Penal Parte Geral. 14. ed. Rio de Janeiro: Ímpetus 2014.

GUPTA, Dipak K. Who Are the Terrorists? Nova Iorque: Chelsea House, 2006.

HAMM, Mark S. A modified social control theroy of terrorismo. P. 105-150. In: HAMM, M. S. (Org.). Hate Crime. Westport: Anderson Publishing, 1994a.

HODGSON, Jacqueline; TADROS, Victor. The Impossibility of Defining Terrorism. The University of Warwick, v. 16, n. 3, p. 494-526, 2013.

HOFFMAN, Bruce. Inside Terrorism. Nova Iorque: Columbia University Press, 2006.

JACOBS, James B.; HENRY, Jessica S. The Social Construction of a Hate Crimes Epidemic. p. 366 - 391. In: The Journal of Criminal Law \& Criminology, vol. 86, n. 2, USA: Northwesteern University Scholl of Law, 1996.

JACOBS, James B.; POTTER, Kimberly. Hate Crimes. Criminal Law \& Identity Politics. Oxford: Oxofrd University Press, 1998.

JAKOBS, Günter. Terroristas como pessoas no direito? Tradução de Luciano Gatti, p. 27 - 36. In: Novos Estudos. CEBRAP 83, março 2009.

, . Bürgerstrafrecht und Feindstrafrecht, in: HRRS, Mai. 2004. Tradução espanhola em Günter JAKOBS e Manuel Cancio Meliá. Derecho Penal del Enemigo. Tradução Manuel Cancio Meliá. Madrid: Cuadernos Civitas, 2003. 
Lehrbuchsverlag, 1983.

,. Strafrecht - Allgemeiner Teil. Die Grundlagen und die Zurechnungslehre. Berlin:

, . A Nova Dogmática Penal e a Política Criminal em Perspectiva Comparada. Ciência e Política Criminal em Honra de Heleno Fragoso. Rio de Janeiro: Forense, 1992.

JESCHECK, Hans-Heinrich. Selbstdarstellung, S. 70-94. In: HILGENDORF, Eric (Hrsg.) Die deutschsprachige Strafrechtswissenschaft in Selbstdarstellungen. Berlin/ New York: Walter De Gryter, 2010.

Humbolt, 1998.

. Lehrbuch des Strafrechtes. (Herausgegeben von Theo Vogler). Berlin: Duncker \&

KOVARICK, L. Sobre a vulnerabilidade socioeconômica e civil: Estados Unidos, França e Brasil. Revista Brasileira de Ciências Sociais, São Paulo, v. 18, n. 51, p.61-85, fev. 2003.

LAMARCA PÉREZ, Carmem. Noción de Terrorismo y Classes. Evolucion Legislativa y politicocriminal.

LENZA, Pedro. Direito constitucional esquematizado. 20 ed. São Paulo: Saraiva, 2016. v. 1. MARCONI, M. de A. LAKATOS, E. M. Metodologia do trabalho científico. 6. ed. São Paulo, SP: Atlas, 2001.

MARSHAL, Alfredo. Principles of economic. Londres: Macmlliam, 2011.

MAZZUOLLI, Valério de Oliveira. Curso de Direito Internacional Público. 9. Ed. Rev., atual. E ampl. São Paulo: Editora Revista dos Tribunais, 2015.

MELO, Miguel; ALMEIDA, André Jorge Rocha de; SILVA, Cícera Rosana da; TEIXEIRA, Emerson Giorgio F. de Aquino. Hate Crimes: uma ressignificação ou nova representação da Criminologia e do Direito Penal Internacional no cotidiano brasileiro? (p. 141-162). In: MELO, Miguel Ângelo Silva de; GOMES FILHO, Antoniel dos Santos; QUEIROZ, Zuleide Fernandes. (Orgs.). Epistemologias em confronto no direito: reinvenções, ressignificações e representações a partir da interdisciplinaridade. Curitiba: CRV, 2017.

MORAES. Alexandre Roxa Almeida de. A terceira velocidade do Direito Penal: 'o direito penal do inimigo'. Dissertação (Mestrado em Direito Penal). Faculdade de Direito da Pontifica Universidade Católica de São Paulo: São Paulo, 2016.

MÜNKLER, Herfried. Die Neuen Kriege, p. 178-184. In: Der Bürger im Staat: Kriege haben ihre Gestalt fundamental verändert., Baden-Württemberg: Herausgegeben von der Landeszentrale für politische Bildung, 2002

NUNES, Paulo Vitor Silva. Lei Antiterrorismo no Brasil. Uma análise sobre sua (des)necessidade. TCC (Graduação Direito). Centro Universitário de Formiga (UNIFOR), 2017.

OCANÃ, Mónica Aranda. La política criminal em matéria de terrorismo. In: RIVERA BEIRAS Iñaki (coord). Política criminal y sistema penal. Barcelona: Anthropos, 2005. p.367. 
OEA. Inter-American Convention Against Terrorism. AG/RES. 1840 (XXXII-O/02). Disponível em: <http://www.oas.org/xxxiiga/english/docs_en/docs_items/agres1840_02.htm> Acesso em: 2 nov. 2015.

ONU. Assembleia Geral, Comitê Ad Hoc. Resolução 51/210, Sexta Sessão, dez. 1996. Disponível em: <http://www.un.org/documents/ga/docs/57/a5737.pdf>. Acesso em: 12 nov. 2015.

PERRY, Barbara. In the Name of Hate. Understanding Hate Crimes. Routledge. New York. 2001.

PROCÓPIO, Argemiro. Terrorismo e relações internacionais. Revista Brasileira de Relações Internacionais, v. 44, n. 2, p. 62-81, 2001.

SILVA, Laís Rivelli. A lei Antiterrorismo. Um reflexo da expansão terrista no Direito Penal no Brasil. TCC (Graduação Direito). Faculdade de Direito da Universidade Federal de Juiz de Fora (UFJF), 2016.

USA Patriot Act. Uniting and strengthening america bynproviding appopriate tools required to intercept and obstruct terrorism, 2001. In: USA Departament's of justice. Disponível em <http://www.gpo.gov/fdsys/pkg/PLAY-107pob56.pdf>. Acesso em: 2 set. 2017.

WHITTAKER, David J. Definição de Terrorismo. In: Terrorismo: um retrato. (Tradução: Joubert de Oliveira Brízida). vol. 422. Rio de Janeiro: Biblioteca do Exército Editora, 2005. 488 p.

WOODWARD, Kathryn. Identidade e diferença: Uma introdução teórica e conceitual. 07-72. In: SILVA, Tomaz Tadeu (org.). Identidade e diferença: a perspectiva dos estudos culturais. Stuart Hall, Kathryn Woodward. 10 ed. Petrópolis, RJ: Vozes, 2011.

ZAFFARONI, E. Raúl. O Inimigo no Direito Penal. Coleção Pensamento Criminológico.

Vol.14. Rio de Janeiro-RJ: Editora Revan, 2007.

\section{Como citar este artigo (Formato ABNT):}

SILVA, Cícera Rosana da; IFADIREÓ, Miguel Melo; ALBUQUERQUE FILHO, José Antônio de. O Debate Criminológico e Dogmático sobre a Incidência do Terrorismo no Direito Penal Brasileiro. Id on Line Rev.Mult. Psic., 2018, vol.12, n.42, p. 561-583. ISSN: 1981-1179.

Recebido: 04/10/2018;

Aceito: 08/10/2018 